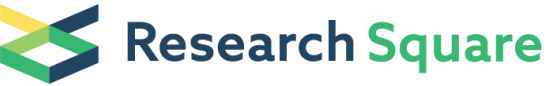 \\ Preprints are preliminary reports that have not undergone peer review. \\ They should not be considered conclusive, used to inform clinical practice, or referenced by the media as validated information.
}

\section{Sjögren's Syndrome in Children: About 15 Cases in Guinea Conakry}

\section{Kaba Condé}

Gamal Abdel Nasser University of Conakry Faculty of Medicine Pharmacy and Odonto-Stomatology: Universite Gamal Abdel Nasser de Conakry Faculte de Medecine Pharmacie et Odontostomatologie

\section{Carlos Othon Guelngar ( $\nabla$ carl325@yahoo.fr)}

Gamal Abdel Nasser university of conakry

\section{Mamadou Ciré Barry}

Gamal Abdel Nasser University of Conakry Faculty of Medicine Pharmacy and Odonto-Stomatology: Universite Gamal Abdel Nasser de Conakry Faculte de Medecine Pharmacie et Odontostomatologie Hugues Ghislain Atakla

University of Benin Teaching Hospital

\section{Awada Mohamed}

Gamal Abdel Nasser University of Conakry Faculty of Medicine Pharmacy and Odonto-Stomatology: Universite Gamal Abdel Nasser de Conakry Faculte de Medecine Pharmacie et Odontostomatologie

\section{Fodé Cissé}

Gamal Abdel Nasser University of Conakry Faculty of Medicine Pharmacy and Odonto-Stomatology: Universite Gamal Abdel Nasser de Conakry Faculte de Medecine Pharmacie et Odontostomatologie

\section{Case report}

Keywords: Sjögren's syndrome, children, Guinea Conakry

Posted Date: May 3rd, 2021

DOI: https://doi.org/10.21203/rs.3.rs-288576/v2

License: (9) This work is licensed under a Creative Commons Attribution 4.0 International License. Read Full License 


\section{Abstract}

Objectives-Sjögren's syndrome is difficult to diagnose in the African context. It is rarely reported in children in Black Africa. We report a series of 15 cases of Sjögren's syndrome in order to clarify the particularities of this condition in children.

Methods- This 2-year retrospective study focused on children under 16 years of age with a male predominance who were followed for AS in the rheumatology and pediatrics departments. Patient data were collected and analyzed using STATA/SE version 11.2 software. Anonymity and respect for ethical rules were the norm. There was no link between patients and researchers.

Results- The average age of the patients was 11 years with extremes of 5 to 15 years. An anamnesis revealing dry mouth was found in more than half of the cases, i.e. in $10(66.7 \%)$ patients. The clinical examination found oral ulceration and periodontitis in equal proportions, i.e. $6(40 \%)$. The immunological assessment and the biopsy of the accessory salivary glands were used as diagnostic evidence in the 15 patients according to the American-European criteria of 2002.

Conclusion-Sjögren's syndrome is a rare entity in pediatrics. It is difficult to diagnose in pediatrics and its severity is linked to the occurrence of visceral and lymphomatous late dry syndrome. Rapid diagnosis and the use of a synthetic antimalarial drug (Hydroxychloroquine) increases the hope of a cure.

\section{Introduction}

Sjögren's syndrome (SS) is a rare autoimmune disease, most often secondary in children associated with other autoimmune diseases [1]. It affects girls much more than boys [2] and is characterized by a dry eye, mouth and in about one third of patients, the pathology is more systemic and can affect various organs [3]. Diagnosis is difficult in children because of their inability to accurately list their symptoms and the difficulty in obtaining reliable data on their personal and family history. Diagnosis is based on a combination of biological and immunological clinical signs and biopsy of accessory salivary glands [4]. Prompt diagnosis is necessary to prevent early complications, especially functional ones related to dry and late syndrome such as visceral and lymphomatous [5].

Frequently encountered clinical manifestations are related to autoimmune exocrinopathy with xerostomia; xerophthalmia; dental caries; periodontitis; dysphagia; dysgeusia and keratoconjunctivitis [6].

In spite of the numerous diagnostic criteria of SS, a controversy persists as to the choice of a precise diagnostic criterion especially in children. Adapting the American-European consensus group (AECG) classification, Bartounkova and Al proposed a new scheme for the diagnosis of AS in children $[7,8]$. We report 15 cases of AS in children.

\section{Patients And Methods}


This was a retrospective study conducted over a 2-year period from August 15, 2018 to August 15, 2020. We targeted patient records (246) followed in the rheumatology and pediatrics department of the lgnace Deen National Hospital, Conakry for an SS. The study focused exclusively on children under the age of 16 years who were followed for an SS. The diagnosis of AS was selected in accordance with the AmericanEuropean consensus criteria and Vitali's criteria for secondary AS. The data analyzed were sociodemographic (age, sex), clinical (dry oral, ocular, skin, bronchial, ENT), joint, peripheral and axial involvement. Clinical forms: primary and secondary SS (associated with another autoimmune disease). Paraclinical data: immunological (anti-nuclear antibodies, anti-SSA and SSB antibodies). Biopsy of accessory salivary glands according to the Schisolm and Mason classification). Patient data were collected and analyzed using STATA/SE version 11.2 software. All parents and, if possible, capable children (16 years of age) signed consent forms before being included in the study. It was made clear that if patients did not wish to participate in the study, this would not affect the quality of their care.

\section{Results}

Of the 15 patients followed in this study, 8 were male and 7 were female with an M/F sex ratio equal to 1.14. The mean age of the patients was 11 years with extremes of 5 to 15 years. The anamnesis revealed dry mouth, nose and eyes in 10 (66.7\%), 4 (6.27\%) and 3 (20\%) of the patients respectively. Ocular pain, hypo agueusia, foreign body sensation in the eyes and ocular burning were found in the following proportions: 2 (13.3); 3 (20); 8 (53.3\%); 6 (40\%) (Table I). The clinical examination found oral ulceration in $6(40 \%)$; periodontitis in $6(40 \%)$; parotidomegaly in $5(33.3 \%)$ (Table I). Ocular redness and photosensitivity were observed in comparable proportions (66.7\%) (Table I). Biology showed a normal blood count, an inflammatory syndrome with a mean sedimentation rate of $55 \mathrm{~mm} / \mathrm{h}$ (extreme 5 and 130), and a positive C-reactive protein with a mean of $35 \mathrm{mg} / \mathrm{l}$ ( 6 and 78). The immunological check-up routinely performed in all patients showed anti-SSA antibody in 6 children (40\%) and anti-SSB antibody in 8 children (53.3\%) (Table I). Six (6) children (40\%) were diagnosed with a Schisolm and Mason grade IV classification (Table II). In addition, 4 children presented with SS with a grade III Schisolm and Mason classification (Table II). Only three children (6.27\%) had an SS with a normal Schisolm-Mason classification. The clinical forms were dominated by primary AS in 9 cases, while secondary AS was present in 6 cases (rheumatoid arthritis 4 cases, lupus 2 cases). After an ophthalmological examination the patients were put on hydroxychloroquine $500 \mathrm{mg} / 24$ hours.

\section{Discussion}

Sjögren's syndrome is an adult condition with a high frequency in the fourth and fifth decade. It is rare and most often secondary in children and adolescents [6]. We report 15 cases of Sjögren's syndrome in children with a predominance of primitive forms and also noted a male predominance. However, in the literature there is a predominance of female and secondary forms [1]. This finding in our study could be explained by the size of our (smaller) sample. 
Diagnostic research is difficult in children because of the often atypical clinical presentation. The clinical manifestations listed in this study are the same ones commonly cited in the literature [7]. The AmericanEuropean consensus criteria and that of Vitali allowed us to establish the diagnosis in the patients studied in this work. Houghton et al [9] had found $72.5 \%$ of recurrent periodontitis, indeed $40 \%$ of our patients had already presented a periodontitis. The occurrence of periodontitis is a fundamental element that increases the sensitivity of the European diagnostic criterion of Vitali et al [9].

The immunological assessment often reports the presence of antinuclear antibodies. Anti-SSA antibodies were positive in $40 \%$ of children and anti-SSB antibodies in $53.3 \%$. Hamzaoui et al [10]. report that antiSSA antibodies are most common in $54-75 \%$ of cases. Although AS is rare in children, and most often secondary, this study found more cases of primary AS than secondary AS. However, we have not found any data or causal link justifying this etiological disproportion. The schirmer test was positive $(15 \mathrm{~mm}$ of humidification after $5 \mathrm{~min}$ ) in more than half of the patients $(60 \%)$. The treatment is primarily symptomatic with prevention of dental carries and ulcerative keratitis. Even if no systemic therapy has proven to date to be really effective, the synthetic antimalarial drug (Hydroxychloroquine) used in our patients had a satisfactory result. Corticotherapy and immunosuppressive treatment can be initiated in case of multi-visceral disease

\section{Conclusion}

Sjögren's syndrome is a rare entity in pediatrics, we report 15 cases with male predominance and secondary forms. Its diagnosis can be difficult to establish in children because of their inability to describe their symptoms accurately. And its severity is linked to the occurrence of dry and late-onset syndromes such as visceral and lymphomatosis. Prompt diagnosis and the induction of effective treatment will help avoid complications.

\section{Abbreviations}

AECG: American-European consensus group

\section{Declarations}

\section{Acknowledgement}

We would like to thank the researchers and study participants for their contributions

\section{Contributions of the authors}

Kaba Condé was the lead author and designed the research; Carlos Othon Guelngar recruited the data, followed up with patients and performed the data and statistical analyses. Mamadou Ciré Barry, Hugues Ghislain Atakla wrote the first draft of the manuscript, which was critically reviewed by Awada Mohamed, Fodé Abass Cissé. All authors have read and approved the final manuscript. 


\section{Funding}

This research was not funded by any institution, the authors contributed to the effort on a personal basis.

\section{Availability of data and materials}

The datasets used and/or analyzed during the current study are available from

the corresponding author on reasonable request.

\section{Ethical approval and consent to participate}

Ethics Committee of the Ignace DEEN, Academic Hospital, chaired by Doctor Awada Mohamed, Director General of the hospital.

\section{Consent for publication}

Not applicable.

\section{Competing interests}

The authors declare no conflict of interest.

\section{References}

1. Ziza JM. Syndrome de Gougerot-Sjogren. In: Godeau P, Herson S, Piette J, editors. Traité de médecine.Paris: Flammarion; 1996. p. 136-45.

2. Oliveira MA, Rezende NPM, Maia CMF, Gallottini M. Primary sjogren syndrome in a 2-year-old patient role of the dentist in dignosis and dental managment with a 6-year follow-up. international journal of dentistry. 2011;21:471475.

3. Signifie C, Aldape MA, King E. paediatric primary sjogren syndrome presenting with bilateral ranulas: a case report and syctemetic review of literature. Int J Pediatr Otorhinolaryngol. 2017;101:11e19.

4. Vitali C, Bombardieri S, Moutsopoulos HM, et al., The European Study Group on Diagnostic Criteria for Sjogren's syndrome. Assessment of the European classification criteria for Sjogren's syndrome in a series of clinically defined cases: results of a prospectivemulticentrestudy.AnnRheumDis1996; $55: 116-21$.

5. Majdoub I, Kallelb S, Hsairia M, et al. Syndrome de Goujerot-Sjogren primitif de l'enfant: à propos d'un cas, Primary Sjogren syndrome in a child. Archives de Pédiatrie. 2017;pag:1-4. https://doi.org/10.1016/j.arcped.2017.09.009.

6. Cimaz R, Casadei A, Rose C, et al. Primary Sjogren syndrome in the paediatric age: a multicentre survey. Eur J Pediatr. 2003;162(10):661e665. 
7. Bartunkova J, Sediva A, Vencovsky J, Tesar V. Primary Sjogren's syndrome in children and adolescents: proposal for diagnostic criteria. Clin Exp Rheumatol. 1999;17(3):381e386.

8. Pierre Y, Jacques-Olivier P. Le syndrome de Gougerot-Sjogren primitif: une actualisation. Joint Bone Spine. 2016;83:166-8. http://dx.doi.org/10.1016/j.rhum.2016.02.004.

9. KRISTIN H, PETER M, ROSS DAVIDC. P, LORI T. Primary Sjogren's syndrome in children and adolescents: are proposed diagnostic criteria applicable? J Rheumatol. 2005;32:2225-32. http://www.jrheum.org/content/32/11/2225.

10. Njim,C.Attig,M.Kairallah AHamzaoui*,OHarzallah,SAttia,L, Zachama A, Mahjoub S. Le syndrome de Goujerot-Sjogren juvénile: à propos de 3 cas; Archives de Pédiatrie 2010;17:1531-4. https://doi.org/10.1016/j.arcped.2010.08.003.

\section{Tables}


Table I: Socio-demographic characteristics of patients, clinical manifestations and paraclinical data of dry syndrome

\section{Variables \\ Socio-demographic characteristics}

Effective (\%) $\mathrm{N}=15$

Sex

Male

Female

Average age (extreme)
$8(53,3 \%)$

$7(46,7 \%)$

11 years (5 et 16 years)

\section{Clinical events}

Dry mouth

Oral ulceration

Mouth-sticky foods

Oral pain

Hypo agueusia

Periodontitis

Parotidomegaly

Foreign body sensation in the eyes

Eye burn

Eye redness

Photosensitivity

Absence of tears

Nasal dryness

Schimer test

\section{Immunological assessment}

Anti-SSA antibodies

Antibodies to SSB
$10(66,7 \%)$

$6(40 \%)$

$4(26,7 \%)$

$2(13,3 \%)$

$3(20 \%)$

$6(40 \%)$

$5(33,3 \%)$

8 (53,3\%)

$6(40 \%)$

9 (60\%)

$10(66,7 \%)$

$3(20 \%)$

$4(26,7 \%)$

9 (60\%)
$6(40 \%)$

$8(53,3 \%)$ 


\begin{tabular}{lcc}
\multicolumn{3}{l}{ Table II: Schisolm and Mason classification } \\
\hline Stades & Effective & Percentage \\
\hline Normal & 3 & $20 \%$ \\
Grade I & 2 & $13,3 \%$ \\
Grade II & 0 & $0 \%$ \\
Grade III & 4 & $26,7 \%$ \\
Grade IV & 6 & $40 \%$ \\
Total & 15 & $100 \%$ \\
\hline
\end{tabular}

